http://jmscr.igmpublication.org/home/ ISSN (e)-2347-176x ISSN (p) 2455-0450 crossref DOI: https://dx.doi.org/10.18535/jmscr/v8i5.82

\title{
To Assess the Effectiveness of Low-dose Granisetron on Shivering in epidural block: A prospective randomized controlled study
}

\author{
Authors \\ Dr Praveen Kumar Tiwari ${ }^{1}$, Dr Shakti Kumar ${ }^{2 *}$, Dr (Prof) Usha Suwalka ${ }^{3}$ \\ ${ }^{1,2,3}$ Department of Anaesthesiology, RIMS, Ranchi, India \\ *Corresponding Author \\ Dr Shakti Kumar \\ Department of Anaesthesiology, RIMS, Ranchi, India
}

\begin{abstract}
Shivering after central neuraxial blockade is unpleasant not only for patients but for anaesthesiologists as well as it induces hypoxemia, lactic acidosis, increased intraocular pressure and intracranial pressure, increased chances of myocardial ischemia and interference with patient's monitoring. Serotonin antagonists reduces the incidence of shivering in patients with spinal anesthesia. Granisetron is better than ondansetron with longer half life and fewer side effects. After getting approval from the ethical committee 32 patients aged between 20-50 years of ASA group I \&II were studied over a period of 2 months. Patients of test group $G$ were given granisetron $10 \mu \mathrm{g} / \mathrm{kg}$ body weight intravenously before anaesthesia whereas group $C$ was control group. The administration of low dose granisetron reduced the incidence of shivering as well as the degree of intensity of shivering post epidural anaesthesia.

Keywords: Shivering, Granisetron, Epidural block.
\end{abstract}

\section{Introduction}

Shivering is unpleasant and causes several undesirable physiologic consequences such as increase in oxygen consumption, carbon dioxide production, chances of myocardial ischemia, infection, bleeding, and minute ventilation. It also induces hypoxemia and lactic acidosis, increased intraocular pressure and intracranial pressure, and interferes with patient monitoring such as ECG, noninvasive blood pressure, and oxygen saturation (SaO2). In regional anesthesia spinal anaesthesia is known to decrease the shivering threshold, preceded by core hypothermia and vasoconstriction above the level of block ${ }^{[1]}$. But no study assessing the effect of granisetron following epidural block is being studied.
Regional anaesthesia may impair thermoregulatory control, and up to a $57 \%$ incidence of shivering during regional anaesthesia has been reported. Shivering during neuraxial anesthesia could have potentially detrimental effects. Regional anesthesia produces vasodilatation, which facilitates core-to-peripheral redistribution of heat ${ }^{[2]}$.

Shivering increases intraocular or intracranial pressure. It also increases the metabolic rate by $100 \%-130 \%{ }^{[3]}$. Shivering is dangerous for patients who suffer from cardiopulmonary diseases $^{[4]}$. Anesthetic agents such as clonidine, magnesium sulfate, ketamine, tramadol, ondansetron, and dexamethasone are often used as 
a premedication. However, these drugs have not significantly reduced the incidence of shivering ${ }^{[5]}$. Serotonin antagonists potentially reduces the incidence of shivering in patients with spinal anesthesia. Granisetron and ondansetron are classified as serotonin antagonist drugs. Ondansetron commonly used as a premedication in regional and general anesthesia ${ }^{[6]}$. Granisetron prevents postoperative nausea and vomiting (PONV) in post chemotherapy. The previous study showed that granisetron is better than ondansetron because it has a longer half-life and has fewer side effects ${ }^{[7]}$. The aim of the study is to determine the effect of low-dose granisetron on shivering incidence in post epidural anesthesia

\section{Materials and Methods}

For this prospective, randomized, controlled, parallel-group study, patients of both sexes, aged between 20 and 50 years, with an ASA physical status of I-II, with Glasgow coma scale 15, were included if they were scheduled to undergo lower half surgeries under epidural anesthesia such as lower limb orthopedic surgeries, lower limb plastic surgeries, or lower abdominal surgeries. Patients were excluded if have any of the following exclusion criteria: 1 . Who refused to participate. 2. Had any contraindications to epidural block. 3. Had a history of hypersensitivity to studied drugs. After approval of the departmental research committee, this study was conducted from $15^{\text {th }}$ september 2019 to $31^{\text {st }}$ march 2020 at Rajendra institute of medical sciences, Ranchi on 60 patients undergoing lower half surgeries after signing a written informed consent. Patients who experienced granisetron side effects, massive bleeding, and epidural block failure were excluded from this study.

Patients were randomized into two groups: the Group C (control group, $\mathrm{n}=30$ ) and the Group $\mathrm{G}$ (granisetron group, $\mathrm{n}=30$ ). Group $\mathrm{G}$ received low-dose granisetron $10 \mu \mathrm{g} / \mathrm{kg}$ body weight (intravenous [IV]) before anesthesia. Room temperature was maintained between $22^{\circ} \mathrm{C}$ and $24^{\circ} \mathrm{C}$. Premedications included tablet alprazolam $(0.25 \mathrm{mg})$ and tablet ranitidine $(150 \mathrm{mg})$ administered orally with a sip of water on the evening before surgery. Intravenous access was secured using $18 \mathrm{G}$ cannula in a nondominant hand and the patient was preloaded with $10 \mathrm{ml} / \mathrm{kg}$ lactated Ringer's solution. Patients were placed in the lateral decubitus/midline sitting position, and an 18G Tuohy needle (Epican Tuohy Needle ${ }^{\circledR}$ 18G; Braun, Melsungen, Germany) was introduced at the L3-L4 or L4-L5 interspace in the midline under all aseptic and antiseptic precautions. Epidural catheter was placed after locating the epidural space with the loss of resistance technique (using a syringe containing air). After ensuring no cerebrospinal fluid or blood backflow from the epidural catheter, a test dose of $3 \mathrm{ml}$ lignocaine containing epinephrine (1:200,000) was administered through epidural catheter. The electrocardiogram (ECG) was observed for 2-3 min for tachycardia or any $\mathrm{T}$ wave change. In the absence of significant ECG change, patients were turned in the supine position, and allocated drug was administered over $3 \mathrm{~min}$. Intraoperative fluid was given according to Holliday-Segar formula. General anesthesia was planned in case of failed or inadequate block and the patient was excluded from the study. Blood pressure and pulse rate were measured every $5 \mathrm{~min}$ for the first $60 \mathrm{~min}$. When the blood pressure decreases more than $20 \%$ from the baseline, ephedrine $(5-10 \mathrm{mg}$ ) was given, and the patient was excluded from the study. The presence of shivering is recorded. If patients experienced shivering, Tramadol $1 \mathrm{mg} / \mathrm{kg}$ body weight (IV) was given.

\section{Statistical Analysis}

Data were analyzed statistically using t-test, regression test, and effective contribution test (standard error [SE]) using SPSS 19 software IBM Corp. Released 2010. IBM SPSS Statistics for Windows, Version 19.0. Armonk, NY: IBM Corp. $\mathrm{P}<0.05$ was considered statistically significant. 


\section{Results}

\begin{tabular}{|l|c|c|c|}
\hline Table 1: Characteristics of the patients $(\mathrm{n}=30)$ & \multicolumn{2}{c|}{ Mean \pm SD } & \\
\hline \multicolumn{1}{|c|}{ VARIABLES } & GROUP C & GROUP G & P Value \\
\hline Age (years) & $28.78 \pm 6.69$ & $31.55 \pm 5.66$ & 0.121 \\
\hline Weight $(\mathbf{k g})$ & $58.79 \pm 9.20$ & $58.67 \pm 9.98$ & 0.882 \\
\hline Height $(\mathbf{c m})$ & $155.82 \pm 6.34$ & $159.56 \pm 27.19$ & 0.900 \\
\hline Temperature before Epidural anesthesia $\left({ }^{\circ} \mathbf{C}\right)$ & $36.56 \pm 0.42$ & $37.22 \pm 0.35$ & 0.603 \\
\hline
\end{tabular}

Table 2: The incidence of shivering postanaesthesia $(n=30)$

\begin{tabular}{|l|c|c|c|}
$\begin{array}{l}\text { Time after } \\
\text { anaesthesia (min) }\end{array}$ & $\begin{array}{c}\text { Group C } \\
\text { n(\%) }\end{array}$ & $\begin{array}{c}\text { Group G } \\
\text { n(\%) }\end{array}$ & P value \\
\hline 20 & $23(76)$ & $0(0)$ & 0.001 \\
\hline 25 & $19(63.3)$ & $0(0)$ & 0.001 \\
\hline 30 & $21(70)$ & $2(6.6)$ & 0.001 \\
\hline 35 & $19(63.3)$ & $2(6.6)$ & 0.001 \\
\hline 40 & $23(76)$ & $2(6.6)$ & 0.001 \\
\hline 45 & $24(80)$ & $6(20)$ & 0.001 \\
\hline 50 & $24(80)$ & $6(20)$ & 0.001 \\
\hline 55 & $24(80)$ & $6(20)$ & 0.001 \\
\hline 60 & $24(80)$ & $6(20)$ & 0.001 \\
\hline Total incidence & 74.28 & 11.08 & 0.001 \\
\hline
\end{tabular}

The subjects for this study were 60 patients who underwent an elective surgery with epidural anesthesia. The characteristics of the patients are shown in Table 1. The mean age of the patients was $28.78 \pm 6.69$ years in the Group $C$ and 31.55 \pm 5.66 years in the Group G. All the data were normal and homogeneous. The shivering incidence in Group C and Group G showed a significant difference. In the first $20 \mathrm{~min}$, after fixation of epidural anaesthesia the shivering incidence in Group C was 76\%, while in Group G, it was $0 \%$ [Table 2]. The shivering incidence in Group C continues to increase until $60 \mathrm{~min}$ post anesthesia. Overall, Group C experienced shivering up to $74.28 \%$, while in Group G, shivering was $11.08 \%(\mathrm{P}<0.005)$. Based on the regression test, low-dose granisetron and observation time influence the shivering incidence $(\mathrm{P}<0.005)$. An effective contribution test $(\mathrm{SE}$ test) was carried out to find the contribution of each factor to the shivering incidence. Based on the SE test, the administration of granisetron made the largest effective contribution (93.46\%). Lowdose granisetron influences the reduction of shivering incidence with $\mathrm{R}^{2}=0.93$. No side effects found in the granisetron group. However, one patient from the control group experienced nausea and vomiting.

\section{Discussion}

Group C experienced shivering up to $74.28 \%$, while in Group $\mathrm{G}$, shivering was $11.08 \%$ ( $\mathrm{P}<$ 0.005). The shivering incidence in Group $C$ continued until the $60^{\text {th }}$ min post anesthesia. The previous study explained that the possibility of shivering incidence in the adult patient is about $20 \%-60 \%{ }^{[8]}$.

In regional anesthesia, the sympathetic nerve blocking leads the vasodilation in the blocked area. Furthermore, the vasoconstriction threshold above the blocked area is decreased by $0.5^{\circ} \mathrm{C}$. Due to that, the body heat transfers from the body core to the peripheral. ${ }^{[9]}$ This process causes heat production-heat loss imbalance and triggers hypothermia. Hypothermia because of neuraxial anesthesia occurs through three phases: redistribution, body heat loss to the environment, and the inhibition of the temperature regulation center. ${ }^{[10]}$

The study showed that in the first $30 \mathrm{~min}$, the redistribution of the body heat to the peripheral caused hypothermia. Both neuraxial and 
granisetron reduce the shivering incidence, but granisetrons's effect is more significant. The shivering incidence starts to elevate in the $45^{\text {th }}$ min post anesthesia. The elevation occurs because the hypothermia already enters the second phase, the heat loss to the environment. In the neuraxial block, the body heat formation is inhibited, especially in the blocked area. The thermoregulation system responses to such conditions by generating shivering. Shivering is also influenced by patient's morphometry, surgery duration, evaporation, and operating room temperature. $^{[10]}$

Granisetron significantly reduces the incidence of shivering. Shivering is related to thermoregulation and regulated by serotonin (5-HT). The uses of serotonin directly in the preoptic region and anterior hypothalamus change the thermosensitive neuron activity. ${ }^{[11]}$

The 5-HT3 antagonist's drug will inhibit serotonin absorption in the preoptic region. The study showed a similar result to Eldaba and Amr's study. ${ }^{[8]}$ In their study, the low-dose granisetron $10 \mu \mathrm{g} / \mathrm{kg}$ body weight was able to reduce the incidence of shivering in children patients. ${ }^{[9]}$

The previous study by Kabade et al. ${ }^{[12]}$ using granisetron $40 \mu \mathrm{g} / \mathrm{kg}$ body weight showed that granisetron reduces the incidence of shivering in adult patients. This study also observed the presence of side effects arising from the granisetron administration. The granisetron group did not experience side effects, but there was one patient who experienced PONV in the control group. The appearance of nausea and vomiting can be caused by hypotension shortly after spinal anesthesia, which is related to hypoxemia or hypoperfusion in the chemoreceptor trigger zone area or vomiting center. ${ }^{[13]}$

\section{Conclusions}

The administration of low-dose granisetron as epidural anesthesia premedication significantly reduced the incidence of shivering and reduced the degree or intensity of shivering post epidural anesthesia. There were no side effects due to the administration of granisetron as premedication.

\section{Financial support and sponsorship: Nil.}

Conflicts of interest: There are no conflicts of interest.

\section{References}

1. Wong PF, Kumar S, Bohra A, Whetter D, Leaper DJ. Randomized clinical trial of perioperative systemic warming in major elective abdominal surgery. $\mathrm{Br} \mathrm{J}$ Surg 2007; 94:421-426.

2. Safavi M, Honarmand A, Mohammad sadeqie S. Prophylactic use of intravenous ondansetron versus ketamine-midazolam combination for prevention of shivering during spinal anesthesia: a randomized double-blind placebo-controlled trial. Adv Biomed Res 2015; 4:207.

3. Lenhardt R. Body temperature regulation and anesthesia. Handb Clin Neurol 2018; 157:635-44.

4. Schwarzkopf KR, Hoff H, Hartmann M, Fritz HG. A comparison between meperidine, clonidine and urapidil in the treatment of post anesthetic shivering. Anesth Analg 2001;92:257-60.

5. Bhattacharya PK, Bhattacharya L, Jain RK, Agarwal RC. Post Anaesthesia Shivering (PAS). Indian J Anaesth 2003; 47:88-93.

6. Nallam SR, Cherukuru K, Sateesh G. Efficacy of Intravenous ondansetron for prevention of postspinal shivering during lower segment cesarean section: A doubleblinded randomized trial. Anesth Essays Res 2017;11:508-13.

7. Chidambaram A, Bylappa K, Somasekaram P. A Comparative Study Of Ondansetron And Granisetron For Prevention Of Nausea And Vomiting Following Laparoscopic Surgeries. The Internet Journal of Anesthesiology. 2010; 29:1-7. 
8. Eldaba AA, Amr YM. Premedication with granisetron reduces shivering during spinal anaesthesia in children. Anaesth Intensive Care 2012;40:150-3.

9. Lenhardt R. Body temperature regulation and anesthesia. Handb Clin Neurol 2018; 157:635-44.

10. Arkiliç CF, Akça O, Taguchi A, Sessler DI, Kurz A. Temperature monitoring and management during neuraxial anesthesia: An observational study. AnesthAnalg 2000; 91:662-6.

11. Ishiwata T. Role of serotonergic system in thermoregulation in rats. J Phys Fit Sport Med 2014;3:445-50.

12. Kabade S, Venkatesh Y, Karthik S, Kumar V. Comparative study of granisetron versus pethidine for the prevention of perioperative shivering under spinal anesthesia. Karnataka Anaesth J 2016;2:14

13. Wong CA. Complication and Side Effect of Central Neuraxial Technique; in Spinal and Epidural Anesthesia. New York: McGraw-Hill; 2007. 